\section{A REVIEW ON THE BENEFITS, BARRIERS OF THE DRONE EMPLOYMENT IN THE CONSTRUCTION SITE}

\author{
Mundher Alsamarraie $a^{*}$, Farid Ghazalia*, Zaid M. Hatemb, \\ Alhamza Yassin Flaihb
}

aSchool of Civil Engineering, Engineering Campus, USM, 14320, Nibong Tebal, Penang, Malaysia

bSchool of Civil Engineering, Faculty of Engineering, Universiti Teknologi Malaysia, 81310 UTM Johor Bahru, Johor, Malaysia
Article history

Received

21 August 2021

Received in revised form

14 November 2021

Accepted

28 November 2021

Published Online

21 February 2022

*Corresponding author Mundher1984@student.usm.my

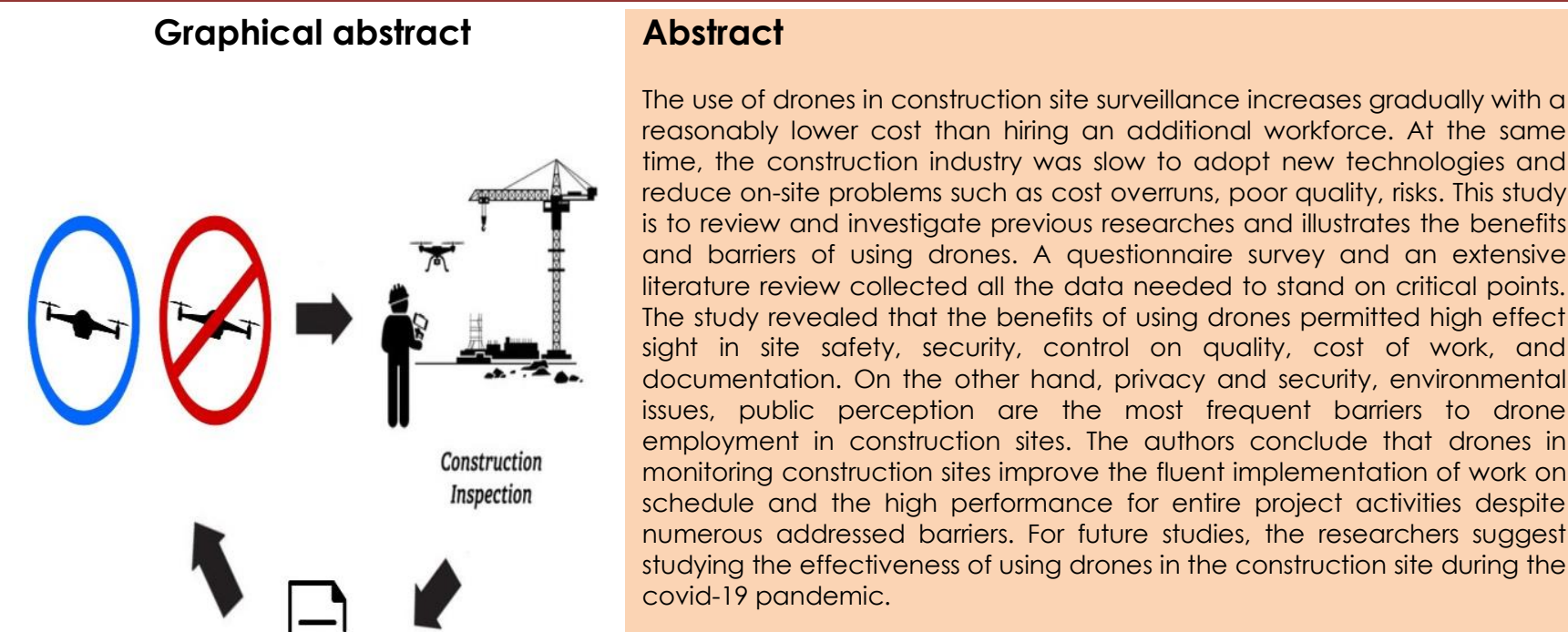

Keywords: Barriers, Benefits, Construction site, Drone, Unmanned aerial vehicles (UAVs)

\subsection{INTRODUCTION}

The construction industry contributed to the extensive employment of workforces [1]. The surveillance of the construction site was a challenging task [2]. Thus, Material flow issues, complexity, internal communication, and external communication are the most common on-site problems [3]. Besides, construction activities include many contributors such as contractors, owners, tradespeople, and subcontractors [4]. The management of construction activities to maximize operational efficiency is an important issue. Therefore, monitoring and tracking the construction projects' performance is vital in 
accomplishing this goal, but it is often complicated because of the constant diversion site environment[5]. Moreover, the widespread Covid-19 pandemic and world health organization (WHO) recommendations for a mandatory lockdown hinder the construction management role and operational efficiency by imposing social distancing[6]. According to some studies, greater than $12.4 \%$ of the construction cost is wasted because of the defective components processing found in the later stages of construction [7]. Also, most buildings' defects refer to human factors, for example, unskilled workers, inadequate oversight, lack of communication and collaboration between contractors and designers, and lack of operational expert solutions during design at the construction site [8].

The construction sector in Iraq is about to see a surge in future projects[9]. Since construction projects of Iraq have a high failure rate linked to cost and schedule, Project planners face a significant obstacle in determining the workplace's required performance because of the difficulty in determining labour productivity [10]. Iraq experienced wide use of several types of drones from various manufacturers for military use after the American invasion in 2003 [11]. According to Iraq drone laws, Iraq allows drones with conditional permissions and some restrictions [12]. The importance of drones emerges clearly in boosting communication and aid in managing projects. It also improves safety, conserves time and effort, expedites surveys, and provides precise measurements [13]. However, the efforts dedicated to solving daily construction problems and development have lacked in the contexts produced by researchers in modern technology adaption and consideration in Iraq. In addition, the researchers started this study in response to the previous calls to investigate the use of drones related to safety and trades off and the broad deployment of drones in the construction sector [14]. It highlights a significant issue and gap in converting efforts to developing practice instead of high losses produced from traditional practice. Past research focused on launching drones to cover fixed paths and managing the construction site to monitor project activities [1, 12]. However, it is still unclear the advantages of using this technology in a wide range. Because of the limited studies to list the benefits and barriers of adopting drones, the research question is, why should we employ drones in a construction site? [16] illustrated that developed software packages help efficiently in the image storage and the creation of slow-motion films. Old procedures of using regular filming cameras are substituted by other innovative ways, such as print and digital formatting [17]. The digital image gives a good capacity for monitoring and documenting the progression of the project and maintaining control of the facility's condition [18]. [16, 17] searched for image databases algorithms and converted digital images in readable 3D environments that track hardware movements. Monitoring the performance and location of determined workplace resources (labour, equipment, and materials) may not be feasible for many reasons. The labourers, for example, do not accept to be monitored or tracked for ethical issues; and consequently, tracking thousands of elements cannot offer a cost-effective (cost-selling technology) or a practical (size or type of material to place tags) approach $[5,14]$. It is crucial to illustrate existing and potential new businesses, inventors, and policy founders about the opportunities for Unmanned Aerial Vehicles (UAVS) in the construction sector. It is in another meaning represents a direct connection drone technology has transformed the process stakeholders view a construction site, reflect a developed project, and produce a considerable added thoughtful interpretation of the process during construction. This research aims to reveal the benefits and barriers to using drones and assess it systematically depending on previous research. The study was limited to the construction sector in Iraq due to each region's different characteristics and nature.

From the above discussions, it is explicit that there is a difficulty with control and a shortage of variation in the construction industry, especially in developing countries [21]. Hence, it is imperative to do this research and conclude whether adopting automated construction technologies will influence the productivity of robots in the construction industry. Innovative system technology can be used in the construction method or the apparatus used to accomplish a construction project. In this research, the machine features of construction technology are reflected, and the researchers reviewed its influences on the workforce in the construction industry. As previous studies justify this concern and still reflect on the importance of ongoing studies on drones used in developing countries throughout their construction industry [22], thus a relevant gap still exists in industries that lack innovative investigation of their application in different sections. A gap is linked with the problem description, needs, and modern studies in the Iraqi construction industry [23].

\subsection{Drone Definition}

Drones are known as Unmanned Aerial Vehicles (UAVs). It is a flying autonomously robot controlled remotely through software-managed flight plans in its built-in systems, working directly in GPS and onboard sensors [24]. Also, it was invented in 1914 in Britain [25]. Different designs of UAVs are based on shapes, mechanisms, and characteristics; it usually designed for specific purposes. Therefore, their hardware and software projects are developed depending on the requirements for tasks. The frame structure of the drone is divided into two types: a fixed-wing and a rotarywing. The fixed-wing drone can fly with wings that generate lift through the front speed and wing shape. The rotary-wing drone can fly with rotating rotors with foil section blades to ensure lifting [26]. This research focused on the rotary-wing drone because of its suitability usage on the construction site. 


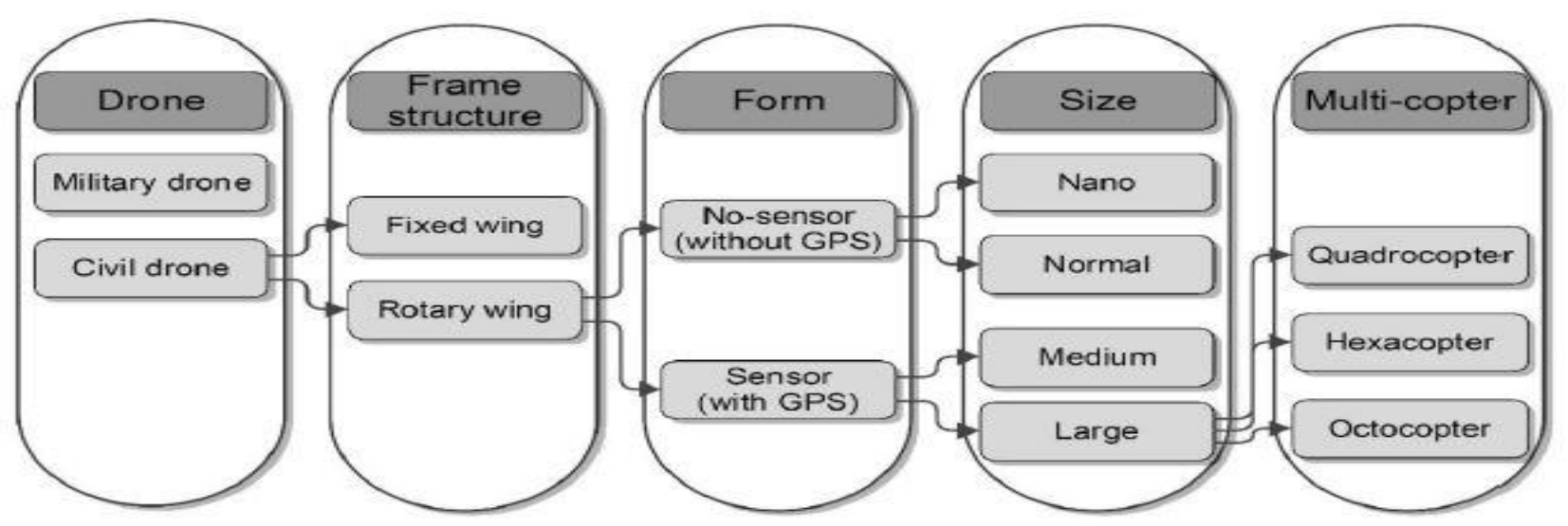

Figure 1 Type of Drones[26]

\subsection{Drone Maintenance and Cost}

Drones come in many types, different specifications, and prices. For professional work, high features drones are needed in the construction works. The construction site's side with drones requires a supported system to extract and process all the images continuously quickly. As to [31], the incurred cost of the drones might involve:

- The cost of the drones themselves.

- Any attached buildings and the drone stations.

- On-site processing system.

- Maintenance engineers.

- Logistics cost.

- Insurance and legal fees.

\subsection{Applications in Construction}

Every case for implementing drone technology in construction schemes is growing year by year. The brand-new methods to characterize drones on their flights become the central relevant part [32]. These technologies empower construction corporations to manage the data obtained from their drones to show methods and develop features of construction management associated to:

1. Estimating

2. Surveying

3. Site monitoring

4. Quality assurance

5. Safety

6. Team report

The drone's ability to correctly survey field ranges is an essential gain of employing drones in construction. Computing, explicitly correlating to estimates of earthwork quantities, is usually prepared by an engineering surveyor and needs a vital significance of time to finish. Nonetheless, applying drones with laser scanners connected with a conventional topographic survey, 3D forms of vast areas can be built in a computer program to classify what earthwork volumes are already on the construction site.
Moreover, visual management (VM) expands traction as a successful approach within lean construction in organization delivery and transparency. The scheme unit and its representatives can approach distinct viewpoints of site processes with a software sight of its live data of drones. The type of transparency can direct to "...simplification and consistency in judgment production and result command, developed work coordination, more detailed description of difficulties and divergence, stimulation of communications amongst production units and widened operator obligation and autonomy.

\subsection{Benefits and Barriers}

The researchers investigated recent studies related to the use of drones in the construction sector. An extensive qualitative method illustrates the frequency of benefits and barriers of using drones in the construction sector. Mapping and surveying with drones have been an outstanding achievement. In order to locate corals, [33] used drones equipped with motion photogrammetry techniques. Researchers found that using high-definition visual cameras mounted on drones to evaluate massive structures in precise detail and diagnose deterioration was both practical and cost-effective [34].

Moreover, drones in irrigation are more economical than satellites since they are not impeded by weather [35]. Using drones to carry medical supplies has proven to be beneficial in the field of healthcare. Drones can distribute and start picking up medicines and testing kits for chronic diseases [36]. In Table 1, the researcher illustrated some benefits to the use of drones. Drones may dissuade people from participating in social gatherings and activities without fear of being videotaped [37]. Drones potentially put the country at risk if they fall into the hands of the wrong people. They can carry out both virtual and actual attacks on the community [38]. In Table 2, the researcher collected possible barriers from previous publication. 
Table 1 Benefits of using Drones in the Construction Industry

\begin{tabular}{|c|c|c|c|c|c|c|c|c|}
\hline No. & Benefits & $\begin{array}{c}\text { R1 } \\
{[27]}\end{array}$ & $\begin{array}{c}\text { R2 } \\
{[26]}\end{array}$ & $\begin{array}{l}\text { R3 } \\
{[5]}\end{array}$ & $\begin{array}{c}\text { R4 } \\
{[28]}\end{array}$ & $\begin{array}{c}\text { R5 } \\
{[29]}\end{array}$ & $\begin{array}{c}\text { R6 } \\
{[30]}\end{array}$ & $\begin{array}{l}\text { Frequency } \\
\text { (N) }\end{array}$ \\
\hline 1. & Better detection & $\sqrt{ }$ & & $\sqrt{ }$ & $\sqrt{ }$ & & & 3 \\
\hline 2. & Reduce cost and high-quality images & $\sqrt{ }$ & $\sqrt{ }$ & $\sqrt{ }$ & & $\sqrt{ }$ & $\sqrt{ }$ & 5 \\
\hline 3. & High mobility & & $\sqrt{ }$ & & & & & 1 \\
\hline 4. & High safety & & $\sqrt{ }$ & $\sqrt{ }$ & $\sqrt{ }$ & $\sqrt{ }$ & & 4 \\
\hline 5. & Short preparation time & & $\sqrt{ }$ & $\sqrt{ }$ & & & & 2 \\
\hline 6. & Real-time monitoring & & $\sqrt{ }$ & $\sqrt{ }$ & $\sqrt{ }$ & & & 3 \\
\hline 7. & scheduling & & & $\sqrt{ }$ & $\sqrt{ }$ & & & 2 \\
\hline 8. & workforce & & & $\sqrt{ }$ & $\sqrt{ }$ & & & 2 \\
\hline 9. & Documents and deliverables & & & $\sqrt{ }$ & & & & 1 \\
\hline 10. & Improve the quality of work & & & & $\sqrt{ }$ & & & 1 \\
\hline 11. & Demolition & & & & $\sqrt{ }$ & & & 1 \\
\hline 12. & surveying & & & & $\sqrt{ }$ & & $\sqrt{ }$ & 2 \\
\hline
\end{tabular}

Table 2 The Barriers Obstacle using Drones in the Construction Industry

\begin{tabular}{|c|c|c|c|c|c|c|c|c|}
\hline No. & Barriers & $\begin{array}{c}\text { R1 } \\
\text { [37] }\end{array}$ & $\begin{array}{c}R 2 \\
\text { [39] }\end{array}$ & $\begin{array}{c}\text { R3 } \\
{[40]}\end{array}$ & $\begin{array}{c}\mathrm{R4} \\
{[41]}\end{array}$ & $\begin{array}{c}\text { R5 } \\
{[29]}\end{array}$ & $\begin{array}{c}\text { R6 } \\
\text { [27] }\end{array}$ & $\begin{array}{l}\text { Frequency } \\
\text { (N) }\end{array}$ \\
\hline 1. & Threat to privacy and security & $\sqrt{ }$ & & $\sqrt{ }$ & & & $\sqrt{ }$ & 3 \\
\hline 2. & regulations & $\sqrt{ }$ & $\sqrt{ }$ & $\sqrt{ }$ & $\sqrt{ }$ & & $\sqrt{ }$ & 5 \\
\hline 3. & Public perception and psychological & $\sqrt{ }$ & & & & $\sqrt{ }$ & & 2 \\
\hline 4. & Environmental issues & $\sqrt{ }$ & $\sqrt{ }$ & $\sqrt{ }$ & & & & 3 \\
\hline 5. & Economic aspects & $\sqrt{ }$ & & & $\sqrt{ }$ & $\sqrt{ }$ & & 3 \\
\hline 6. & Technical issues & $\sqrt{ }$ & $\sqrt{ }$ & $\sqrt{ }$ & & & $\sqrt{ }$ & 4 \\
\hline 7. & Site-related problems & & $\sqrt{ }$ & $\sqrt{ }$ & & & & 2 \\
\hline 8. & weather & & $\sqrt{ }$ & & & & & 1 \\
\hline 9. & Organizational barriers & & $\sqrt{ }$ & & & & & 1 \\
\hline
\end{tabular}

\subsection{METHODOLOGY}

This section clarifies the methodology and design utilized to lead this research. Deciding on a sound research methodology be the procedure and management of data to answer and solve the question, including hypothesis testing, to reach a beneficial conclusion. This chapter will describe the research design and methodology used to achieve this research. All questions put in our research questionnaire is designed to answer the research. Quantitative research completes three primary aspects: conceptualizing reality and factors, measuring them, and considering connections. Quantitative information collection mostly takes time and is considered time-consuming as the example measure is generally more prominent than subjective. Compared with individuals. The aspects which will focus on:

1) Design of the Research.

2) Research sampling, location, and population.

3) Research Instrumentation.

4) Procedures.

5) Data analysis.

\subsection{Population, Location, and Sampling Techniques}

The research methodology received for this study is a questionnaire survey. Information collected from one section is fundamental to detail and breaks down the data from the other part. Therefore, all questions put in our research questionnaire are designed to answer the research objectives and match certain stages from previous works. The research population is the contractors, sub-contractors, clients, engineers, consultants in Iraq. The researcher has taken the results of 120 responses to the targeting sample. This driven respondent sampling method in a hidden population guarantees that each person gets the same probability of taking as a sample.

\subsection{Research Instrumentation}

A survey questionnaire was implemented to specify the barriers and benefits of Drones in construction sites, then to discuss the survey results. The questionnaire was applied to collect information from respondents, such as their perceptions, attitudes, and opinions about the research event. This questionnaire is 
categorized into three parts A, B, and C. Sections B and $C$ have a total number of questions that reach 40 to cover all potential aspects of our research.

\section{Section A}

This section compromises the background and general information of the respondents, their job, level of education, the age of an organization, the type of buildings that the organization develops, and their experience in the construction industry-the data obtained from this section used for demography analysis.

\section{Section B}

In this section, the researcher collects the information and responses relating to the benefits and barriers to using Drones in the construction industry from different perspectives in the subjective matter then tries to match all the most common factors to develop a model for each part.

\section{Section C}

In this section, the researcher asks questions about the benefits and barriers addressed in the literature review using the Likert scale to show each method's impact. In addition, the researcher persists in identifying the most frequent barriers and benefits in previous studies among all these implemented in the construction site.

\subsection{Data Analysis}

The questionnaire was analyzed taking the software of Statistical Package for Social Science (SPSS). The usage of this software calculates essential information such as frequency, percentage, and mean. This software helps the researcher consider the records easier, precise, faster, and more accurate than manual methods. The outcomes will indicate whether or not the consequences of this study collaborate with the goal of this research. The statistical analysis will produce a result that can be evaluated in a desk structure and confirmed facts, for instance, frequency and percentage. Every objective mentioned from the information analyze based totally on the questionnaire. The credibility and the weight of the research depend enormously on the reliability and validity of the collected data. Information is regularly thought of as 'the facts' - the things that seem to be correct. In any case, indeed, information is a social item. The essential data collection refers to the firsthand data collected directly by the researcher to use for their study. Moreover, this data is obtained by directing individual examinations through respondents and review utilizing a questionnaire.

\subsection{RESULTS AND DISCUSSION}

The result of the survey questionnaire achieved the results shown below. The Authors distributed the questionnaire using google forms among professionals and employees, and they deal with construction in their daily routines. A total number of 120 survey questionnaires was distributed, the respondents have given their feedback and contribution.

\subsection{Reliability Test}

A reliability test was conducted to show the questions' suitability to work in the questionnaire group. The value of the Alpha Cronbach test for all items illustrates that it is reliable. Alpha Cronbach's value of each section in the questionnaire should be greater than 0.7 to meet an acceptable level [42]. The table shows that $a=0.89$ for section 1 and 0.83 for section 2. Thus, it is a good indication that the design of questions inside the questionnaire is working as groups, and the instrument is reliable, as shown:

Table 3 Reliability test for section C Part 1

\begin{tabular}{|cc|}
\hline \multicolumn{2}{|c|}{ Reliability Statistics } \\
\hline $\begin{array}{c}\text { Alpha Cronbach } \\
\text { test }\end{array}$ & N of Items \\
0.89 & 10 \\
\hline
\end{tabular}

Table 4 Reliability test for section C Part 2

\begin{tabular}{|c|c|}
\hline \multicolumn{2}{|c|}{ Reliability Statistics } \\
\hline $\begin{array}{c}\text { Alpha Cronbach } \\
\text { test } \\
0.83\end{array}$ & $\begin{array}{c}N \text { of Items } \\
30\end{array}$ \\
\hline
\end{tabular}

\subsection{Background of Respondents}

In this part, the data was analyzed for the background of the company and the project. The first analysis would be the position of the respondents, as shown in Table 5.

Table 5 The Position of Respondents

\begin{tabular}{lll}
\hline No. & Respondent & Percentage \\
\hline 1 & Property Developer & $19 \%$ \\
2 & Site Engineer & $41 \%$ \\
3 & Contractor & $12 \%$ \\
4 & Consultant & $15 \%$ \\
5 & Building Control & $13 \%$ \\
& Officer & \\
\hline
\end{tabular}

A significant group of respondents works at the site or indirect activities on the site. Thus, $41 \%$ of the respondents work as site engineers, and $19 \%$ represent property developers. It is merely their nature of work that needed them to monitor work progress on-site 
compared to anyone else continuously. So, that gives us practical and trusted information for this survey. $15 \%$ of the respondents work as consultants, and $13 \%$ and $12 \%$ refer to building control officers and contractors, respectively.

The results in Figure 2 show that $36 \%$ of the companies are at the age of service from 11-20 years. Moreover, in the same percentage for the companies from 6-10 years. In less rate, we can find that the companies with years of service bigger than 20 years come in third place recorded $17 \%$ of the total sample, and the new companies only represent $12 \%$. Thus, we can conclude from all the percentages above that our survey passed on numerous experienced companies to deal with our survey questions.

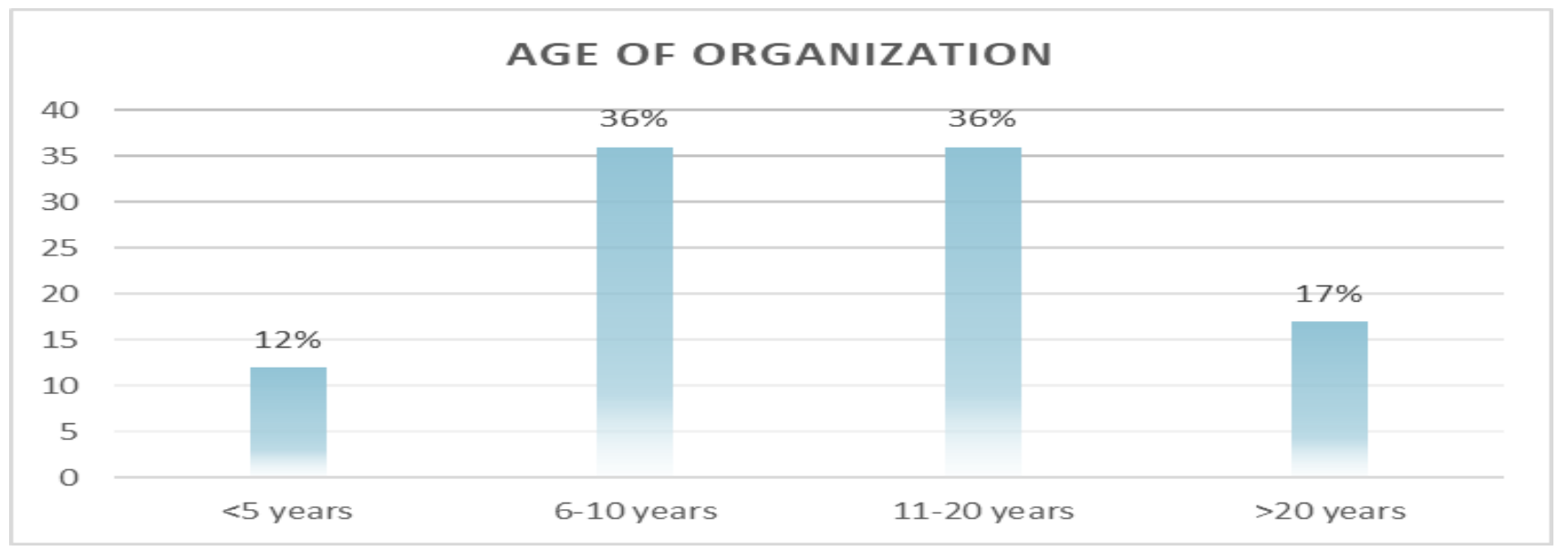

Figure 2 Year of service for the company

The researcher analyzed the projects that participated in this study; the results of the analysis shown in Figure 3, the majority of respondents came from High building projects (housing), which contribute $49 \%$ of the total data. It is because many residential building projects are undertaken compared to other projects. Commercial projects came after residential projects with $32 \%$. and industrial projects came lastly with $19 \%$.

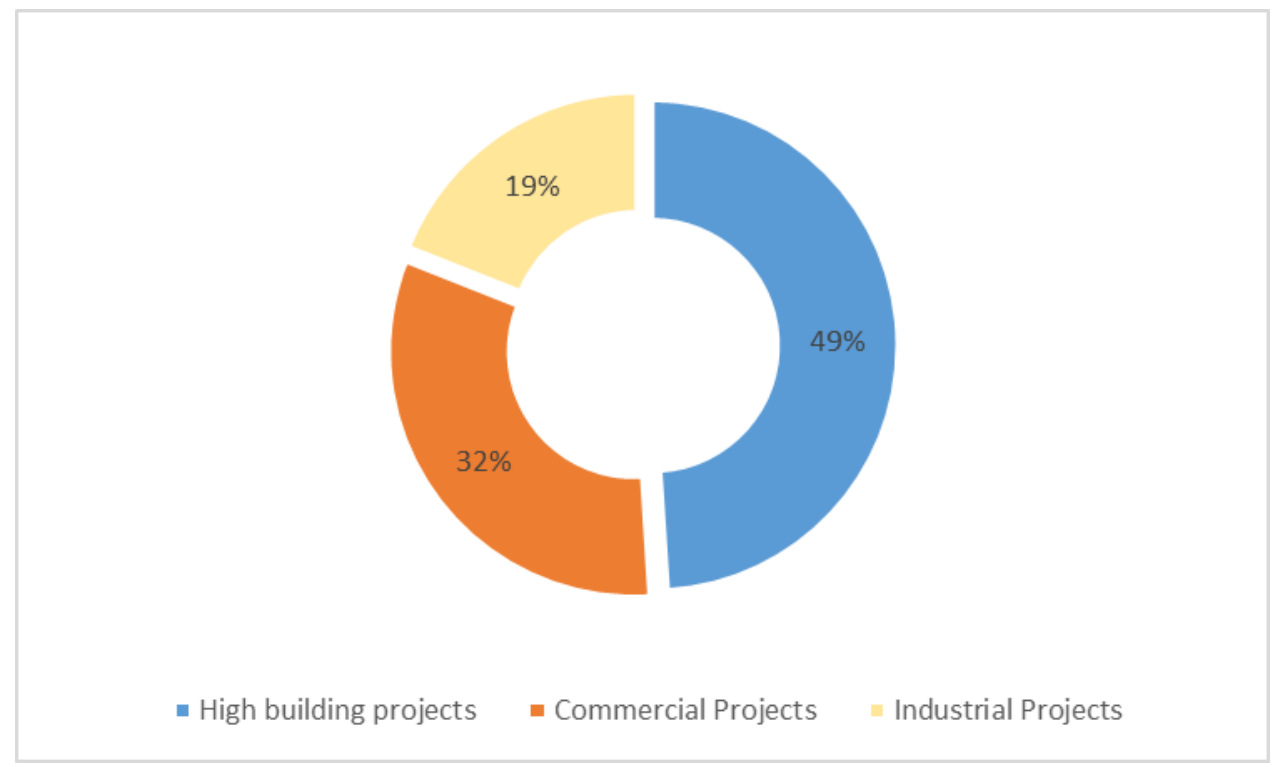

Figure 3 Type of Buildings

\subsection{Drone adoption benefits from the data collected}

The authors addressed the benefits of adopting drone technology in this questionnaire survey, and they classified these benefits in four categories project performance, documentation, administration, and health and safety as shown in Figure 4. These benefits described statistically as illustrated in Figure 5. 
The use of drones will improve the performance of the workforce keep it on schedule. In addition, fluent implementation of project work activities, control on the quality of the achieved work, reduce cost and short work, safety and risk avoidance, real-time inspection, assist in the documentation work and report preparation, low insurance cost, security purposes, easy and fast transferrable data, and prework detailed surveying. The government should first permit institutes and the public sector to adopt the conditional use of drones in the construction site following governmental regulations for this situation in predefined limits.

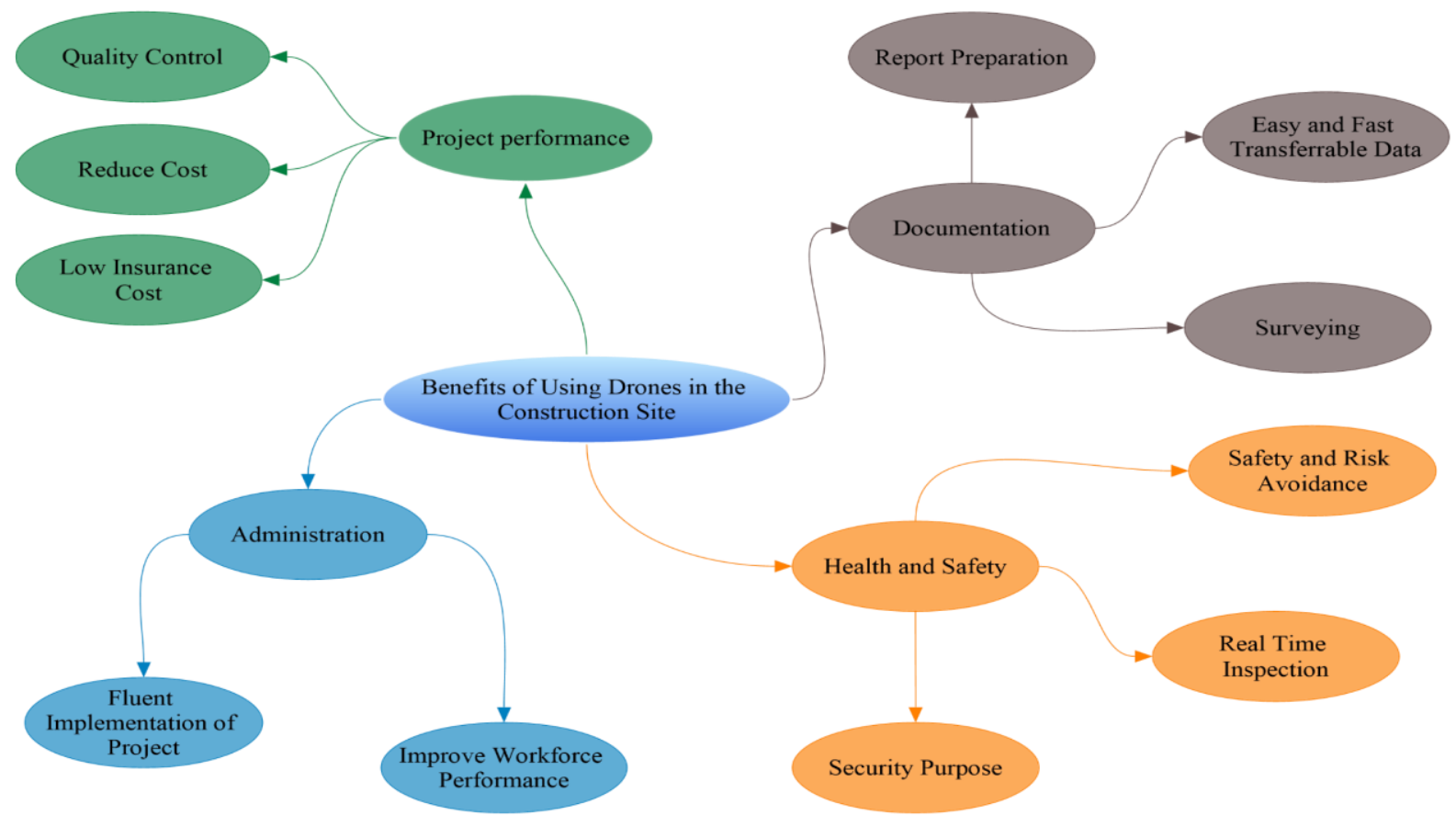

Figure 4 benefits categorization of using drones in the construction sites

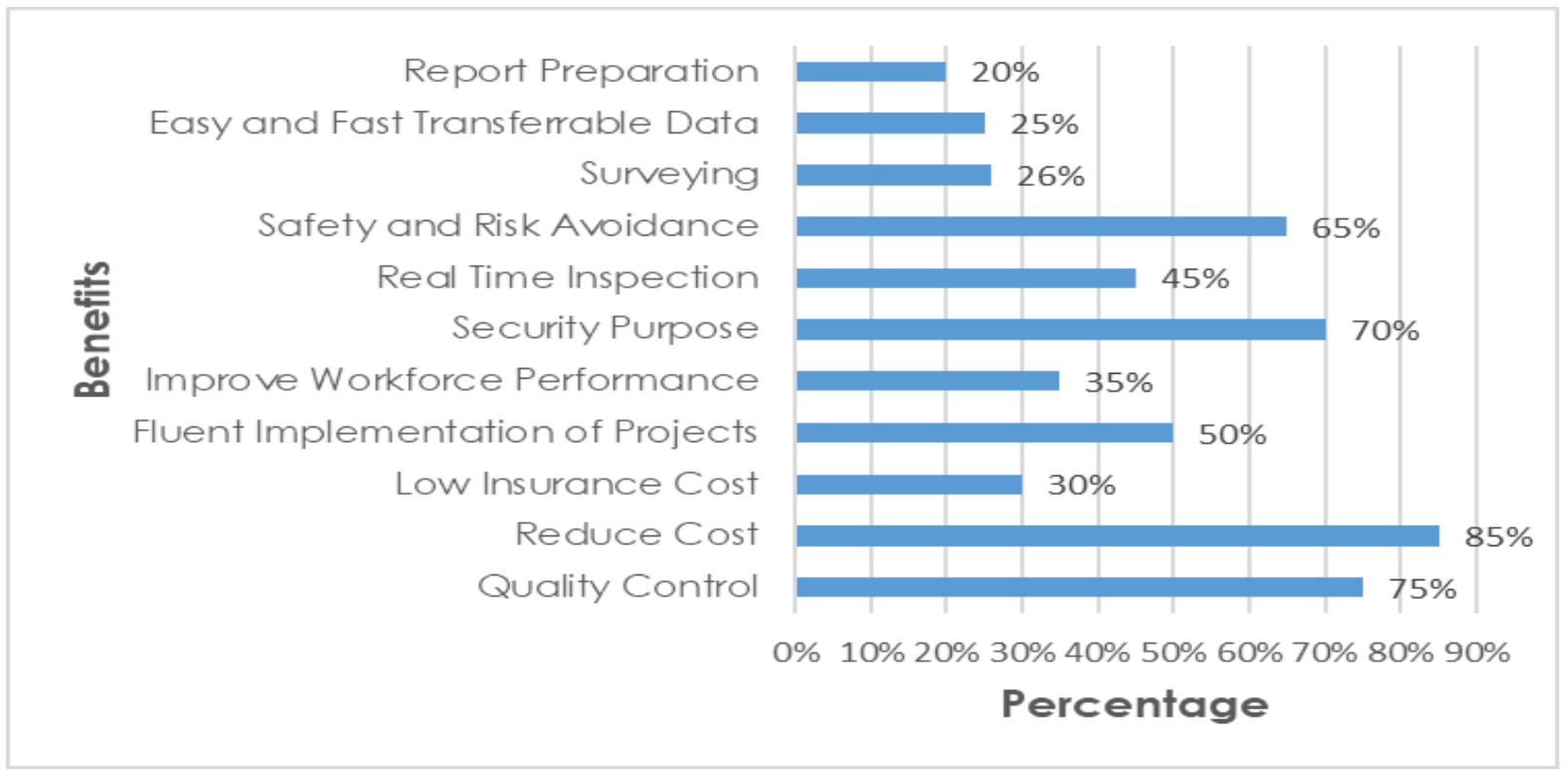

Figure 5 Benefits of Using Drones

\subsection{Barriers to using drones in the construction sites}

The survey collected the different side views of the respondents concerning the common barriers towards the adoption of drone technology in the construction site. Public perception, ethical issues, the threat of privacy and security, government regulations, environmental issues, economic issues, technical 
issues, organizational barriers, cost surplus, cultural issues, and weather conditions are described in Figure 6. The authors clarified the data collected towards the barriers of using drones statistically, as shown in Figure 7.

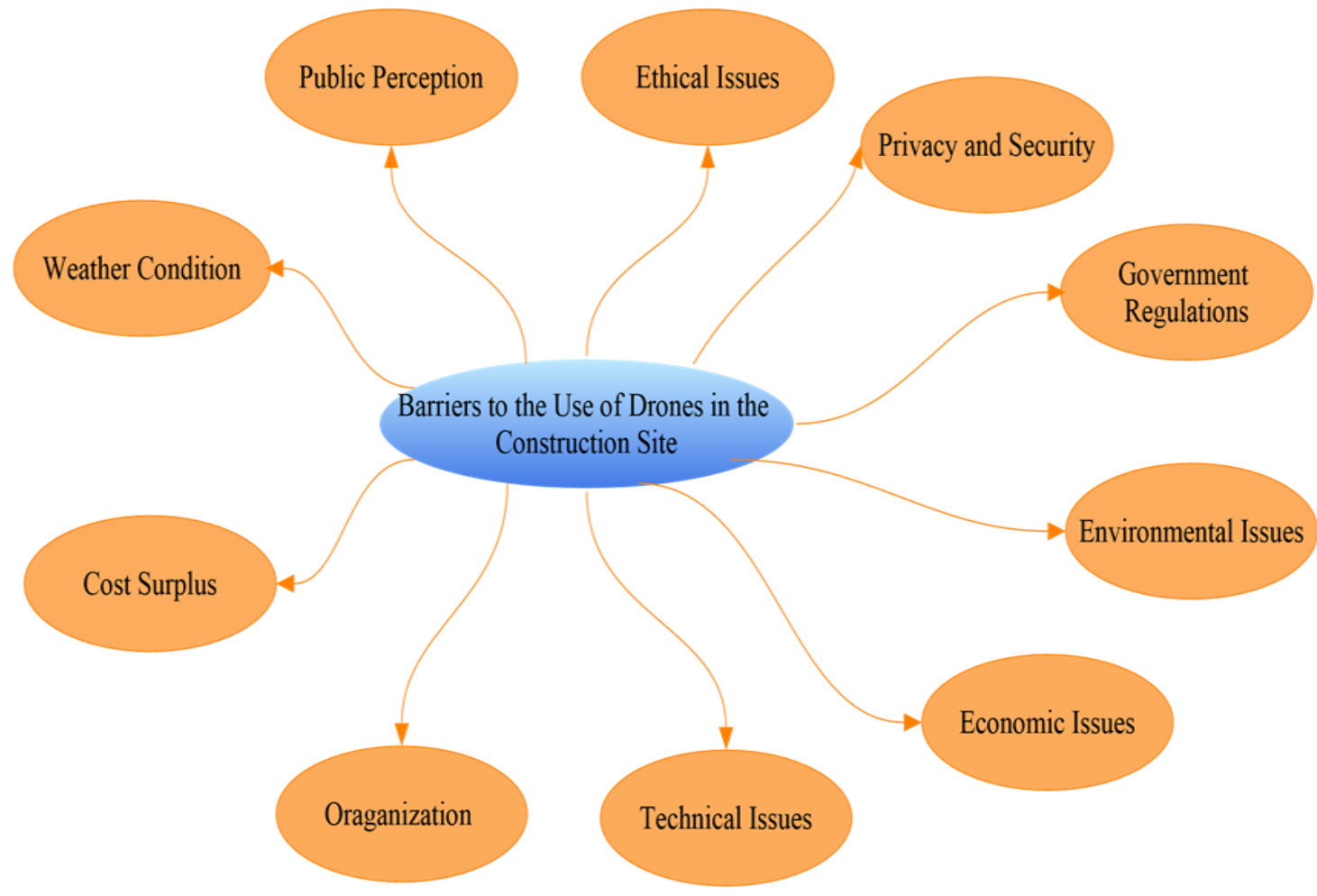

Figure 6 the barriers of using drones in the construction sites

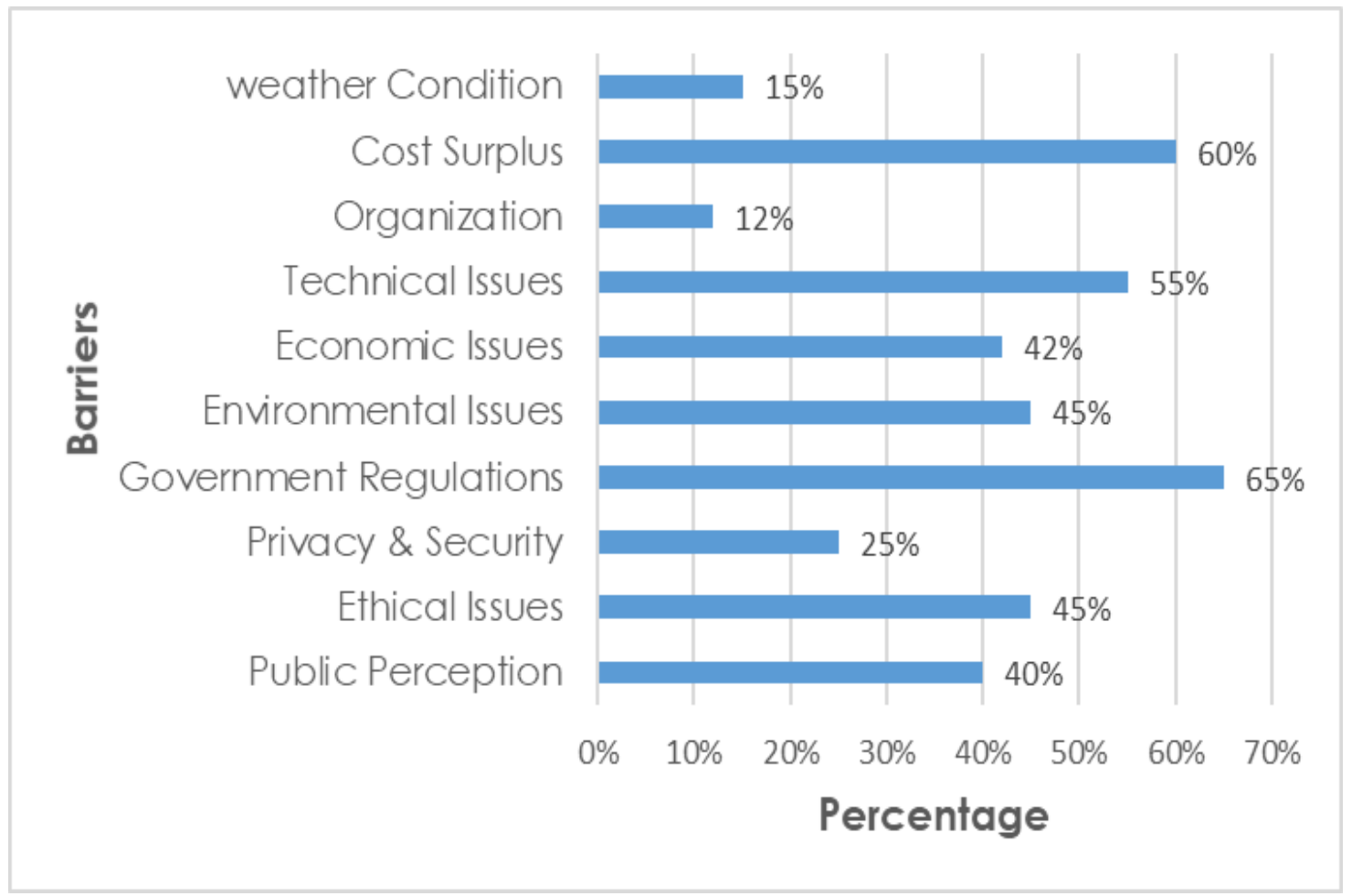

Figure 7 Barriers to using Drones 


\subsection{Discussion}

The researchers investigated recent studies related to the use of drones in the construction sector. The extensive qualitative method illustrates the frequency of benefits and barriers of using drones in the construction sector. Numerous studies have demonstrated the cost-saving effect of deploying drones in the construction sector, as reporting on large and expensive equipment is frequently stressful [43] and minimizes operational costs [36, 37]. Drone technology is being used in several innovative ways, including surveying damaged structures and assessing insurance costs [46]. The flexibility and focus provided by drone-based aerial photography have shifted the balance, giving a cost-effective and timely method of documentation [47]. Drones assist in the collection of construction site records and enhance crane operator visibility $[40,41]$; detect unauthorized activity or entry of workers into a predefined danger zone of plant operation [50]; wireless networks promote autonomy crane safety monitoring [51]. In terms of safety administration, drones are used to automate the surveillance of the real-time locations of all workforce [52], machinery, and materials on a work site by detecting and locating them via sensors or identifiers to generate warnings in particular danger zones [53], prevent accidents and fall, and provide statistics [41, 46]. Early adopters in landscape architecture practice and study use drones to document sites, communicate design concepts, and observe cultural characteristics and natural systems [55]. Using imagebased methodologies for verifying as-built documents for existing structures was investigated, allowing for a comparison of plans and realities [56]. In the second part of this study, the researchers addressed the barriers to the use of drones. Thus, some studies recognized significant impediments include public perception due to societal anxiety about automation [57], noise and public annoyance [46], environmental impacts in terms of $\mathrm{CO}_{2}$ emissions $[50,51]$, technical issues maintenance [60], economic concerns [37], and they take in consideration battery charging, exchange through drone lifecycle [61]. Moreover, government and administrative regulations and restrictions significantly impacted the use of drones [62].drone flies close to the residential areas create privacy and ethical issues[63]. The best conditions for using drones are extended periods of stable weather $[56,57]$.

\subsection{CONCLUSION}

This study uncovered the unique feature of the construction site of Iraq. In this study, the researcher employed the questionnaire survey collecting the respondents' data and matching the data with all the information collected from the literature review concerning the barriers and the benefits of using drones in construction sites. The authors believe that drone employment in the construction site will improve the engineering team's task on many levels, such as site management and site investigation [66]. The intrusion of this technology will be highly beneficial under specific regulations and guidelines of the government [67]. Drones are an emerging technology with vast potential to support future and current Iraqi construction industry needs and practices, including remarkable services over traditional practices related to cost, time, industrial prospect for managers, and construction quality [68].

On the other hand, many obstacles addressed by the experts regarding the adoption of this technology, such as ethical, cultural issues, and government regulations as the main barriers, stand against the use of drones in construction sites. For future research, the authors proposed investigating the mechanism of using drones in construction sites following government regulations and policies. The authors also suggest studying the effectiveness of using drones in the construction site during the covid-19 pandemic. Evergrowing support over the world requires to be investigated to assure relevant serviceability and adequate fundamental integrity. Nevertheless, it demands critical study, and there is an insufficiency for a further practical and affordable technique to examine constructions visually in Iraq. Another concern is the considerable quantity of visual data gathered in single or multiple visits, and it requires a well-prepared database system that employs modern IT systems following drones that Iraq currently lacks. In addition to the principal challenge with visual examination is that collected outcomes can differ significantly depending on the inspector's knowledge and experience[9]. The gaps are addressed in suitable ways that cover the drones' relationship with construction application by highlighting the results of mismanagement and lack of implantation in daily construction duties.

\section{Acknowledgement}

The Authors appreciate the open access of the database of Universiti Sains Malaysia and Universiti Teknologi Malaysia to support their research study.

\section{References}

[1] W. Yi and M. Sutrisna. 2020. Drone Scheduling for Construction Site Surveillance. Comput. Civ. Infrastruct. Eng. 1-11. DOI: $10.1111 /$ mice.12593.

[2] Howard, Howard, J. 2017. Can Drones Make Construction Safer? Retrieved July 25, 2020, from https://blogs.cdc.gov/niosh-scienceblog/2017/10/23/drones-construction/.

[3] M. Thunberg, M. Rudberg, and T. K. Gustavsson. 2017. Categorizing On-site Problems a Supply Chain Management Perspective on Construction Projects. Constr. Innov. 17(1): 90-111. DOI: 10.1108/Cl-10-2015-0059.

[4] J. Yang, M. W. Park, P. A. Vela, and M. Golparvar-Fard. 2015. Construction Performance Monitoring via Still Images, Time-lapse Photos, and Video Streams: Now, Tomorrow, and The Future. Adv. Eng. Informatics. 29(2): 211-224. DOI: 10.1016/j.aei.2015.01.011. 
[5] Mufdillah. 2009. Asuhan Kebidanan Ibu Hamil. 53(9): 16891699. DOI: $10.1017 /$ CBO9781107415324.004.

[6] Alsamarraie, M. M., \& Ghazali, F. 2021. The Impact of COVID-19 and Control Strategies Adoptionin the Construction Sector. Annals of the Romanian Society for Cell Biology. 25(6): 19524-19531.

[7] J. L. Burati, J. J. Farrington, and W. B. Ledbetter. 1992. Causes of Quality Deviations in Design and Construction. J. Constr. Eng. Manag. 118(1): 34-49. DOI: 10.1061/(ASCE)07339364(1992)1 18:1(34).

[8] R. Atkinson. 1999. Project Management: Cost, Time and Quality, Two Best Guesses and a Phenomenon, Its Time to Accept Other Success Criteria. Int. J. Proj. Manag. 17(6): 337-342. DOI: 10.1016/S0263-7863(98)00069-6.

[9] Z. Hatem, M. Alsamarraie, and A. Flaih. 2021. Barriers to the Adoption of Industrialized Building System in Iraqi Construction Industry. Zanco J. Pure Appl. Sci. 33(3): 30-42.

[10] A. J. Dakhil, Z. M. Naji, S. K. Faleh, and A. Lecturer. 2017. Factors Affecting Construction Labour Productivity in Iraq Using Basra City As a Case Study. Kufa J. Eng. 8(3): 55-75.

[11] D. Gettinger. 2016. Drones Operating in Syria and Iraq. Report. Dan Gettinger.

[12] I. D. Laws. 2019. Iraq Drone Laws. Report: https://uavsystemsinternational.com/pages/iraq-dronelaws/.

[13] R. Moret. 2018. The Rise of Drones in Construction. https://www.dronedeploy.com/blog/rise-dronesconstruction/ (accessed Jul. 27, 2021).

[14] R. Merkert and J. Bushell. 2020. Managing the Drone Revolution: A Systematic Literature Review into the Current Use of Airborne Drones and Future Strategic Directions for Their Effective Control. J. Air Transp. Manag. 89(September): 101929. DOI: 10.1016/j.jairtraman.2020.101929.

[15] S. Kim and S. Kim. 2018. Opportunities for Site Monitoring by Adopting First Personal View (FPV) of a Drone. Smart Struct. Syst. 21 (2): 139-149. DOI: 10.12989/sss.2018.21.2.139.

[16] J. Abeid and D. Arditi. 2002. Time-lapse Digital Photography Applied to Project Management. J. Constr. Eng. Manag. 128(6): $\quad 530-535 . \quad$ DOI: $10.1061 /$ (ASCE)0733 9364(2002) 128:6(530).

[17] J. J. Hannon. 2007. Emerging Technologies for Construction Delivery. Transportation Research Board. 372

[18] I. K. Brilakis and A. Arbor. 2007. Long-distance Wireless Networking for Site - Office Data Communications. 12. (March): 151-164.

[19] I. Brilakis and L. Soibelman. 2005. Content-based Search Engines for Construction Image Databases. Autom. Constr. 14(4): 537-550. DOI: 10.1016/j.autcon.2004.11.003.

[20] I. Brilakis, F. Cordova, and P. Clark. 2008. Automated 3D Vision Tracking for Project Control Support. Proc. Jt. US European Work. 487-496. [Online]. Available: http://www.eg-ice.org/Workshops/ICE08/papers pdf/P019V03.pdf.

[21] Z. M. Idris Abdul Rashid, Abdul Rahim Abdul Hamid, Arif Mohd Zainudin. 2019. Unethical Behaviour among Professional in the Malaysian Construction Industry. Proceeding Civ. Eng. UTM. 4: 126-132. DOI: 10.13140/RG.2.2.15778.99523.

[22] H. Agenbag and C. Amoah. 2021. The Impact of Modern Construction Technology on the Workforce in the Construction Industry. IOP Conference Series: Earth and Environmental Science. 654(1): 12001.

[23] N. A. Zaid Mohammed Hatem, Abdul Rahim Abdul Hamid. 2018. Factors that Leads to Poor Welfare Facilities Implementation at Construction Sites in Iraq. Proceeding Civ. Eng. UTM. 4: 72-79. DOI: 10.13140/RG.2.2.3591 1.65448.

[24] Rouse, Rouse, M. (2019, July 15). What is a Drone? Definition from Whatls.com. Retrieved July 30, 2020, from https://internetofthingsagenda.techtarget.com/definition/d rone. 2020.

[25] Gao. 2011. Icptt 2011 @ 2011 ASCE 381. 381-390.

[26] P. Liu et al. 2014. A Review of Rotorcraft Unmanned Aerial Vehicle (UAV) Developments and Applications in Civil Engineering. Smart Struct. Syst. 13(6): 1065-1094. DOI:
$10.12989 /$ sss.2014.13.6.1065.

[27] M. Harbo and O. Vrincianu. 2019. Drones for Inspection of Infrastructure: Barriers, Opportunities and Successful Uses. Cent. Integer. Innov. Manag. SDU.

[28] Y. Li and C. Liu. 2019. Applications of Multirotor Drone Technologies in Construction Management. Int. J. Constr. Manag. 19(5): 401-412. DOI: 10.1080/15623599.2018.1452101.

[29] B. Vergouw, H. Nagel, G. Bondt, and B. Custers. 2016. The Future of Drone Use. Asser Press. 27: 21-46. DOI: 10.1007/97894-6265-132-6.

[30] A. Goodchild and J. Toy. 2018. Delivery by Drone: An Evaluation of Unmanned Aerial Vehicle Technology in Reducing $\mathrm{CO} 2$ Emissions in the Delivery Service Industry. Transp. Res. Part D Transp. Environ. 61: 58-67. DOI: 10.1016/j.trd.2017.02.017.

[31] A. Welch. 2015. A Cost-benefit Analysis of Amazon Prime Air A Cost-benefit Analysis of Amazon Prime Air Project Director: Bruce Hutchinson. Univ. Tennesse Theses. 57.

[32] W. Devers. 2019. A Case Study on the Use of Drones on Heavy Civil Construction Projects. Report. William Devers. https://scholar.google.com/scholar?hl=ar\&as_sdt=0\%2C5\& $\mathrm{q}=\mathrm{W} .+$ Devers.+2019.+A+Case+Study+on+the+Use+of+Drone s+on+Heavy+Civil+Construction+Projects.\&btnG=

[33] E. Casella et al. 2017. Mapping Coral Reefs Using ConsumerGrade Drones and Structure from Motion Photogrammetry Techniques. Coral Reefs. 36(1): 269-275.

[34] N. Hallermann and G. Morgenthal. 2013. Unmanned Aerial Vehicles (UAV) for the Assessment of Existing Structures. IABSE Symposium Report. 101 (14): 1-8.

[35] N. J. Stehr. 2015. Drones: The Newest Technology for Precision Agriculture. Nat. Sci. Educ. 44(1): 89-91.

[36] S. J. Kim, G. J. Lim, J. Cho, and M. J. Côté. 2017. Droneaided Healthcare Services for Patients with Chronic Diseases in Rural Areas. J. Intell. Robot. Syst. 88(1): 163-180.

[37] B. Sah, R. Gupta, and D. Bani-Hani. 2020. Analysis of Barriers to Implement Drone Logistics. Int. J. Logist. Res. Appl. 1-20.

[38] H. Kwon, J. Kim, and Y. Park. 2017. Applying LSA Text Mining Technique in Envisioning Social Impacts of Emerging Technologies: The Case of Drone Technology. Technovation. 60: 15-28.

[39] H. Golizadeh, M. R. Hosseini, D. J. Edwards, S. Abrishami, N. Taghavi, and S. Banihashemi. 2019. Barriers to Adoption of RPAs on Construction Projects: A Task-technology Fit Perspective. Constr. Innov. 19(2): 149-169. DOI: 10.1108/Cl09-2018-0074.

[40] W. McDonald. 2019. Drones in Urban Stormwater Management: A Review and Future Perspectives. Urban Water J. 16(7): 505-518. DOl: $10.1080 / 1573062 X .2019 .1687745$.

[41] M. Mayes and M. Mayes. 2018. Drone Implementation: Regulatory Barrier. University Honors Program Theses. 351 https://digitalcommons.georgiasouthern.edu/honorstheses/351.

[42] J. a Gliem and R. R. Gliem. 1992. Calculating, Interpreting, and Reporting Cronbach's Alpha Reliability Coefficient for Likert-type Scales. 2003 Midwest Res. to Pract. Conf. Adult, Contin. Community Educ. 82-88. DOI: 10.1109/PROC.1975.9792.

[43] R. Westcott. 2013. Hexacopter Changes the Way TV Reporters Work. BBC. Com. 29.

[44] C. C. Murray and A. G. Chu. 2015. The Flying Sidekick Travelling Salesman Problem: Optimization of Drone-assisted Parcel Delivery. Transp. Res. Part C Emerg. Technol. 54: 86109.

[45] Q. M. Ha, Y. Deville, Q. D. Pham, and M. H. Hà. 2018. On the Min-cost Travelling Salesman Problem with Drone. Transp. Res. Part C Emerg. Technol. 86: 597-621.

[46] S. Watkins et al. 2020. Ten Questions Concerning the Use of Drones in Urban Environments. Build. Environ. 167: 106458 ,

[47] T. D. Stek. 2016. Drones over Mediterranean Landscapes. The Potential of Small UAV's (Drones) for Site Detection and Heritage Management in Archaeological Survey Projects: A Case Study from Le Pianelle in the Tappino Valley, Molise (Italy). J. Cult. Herit. 22: 1066-1071. 
[48] Y. Li and C. Liu. 2012. Integrating Field Data and 3D Simulation for Tower Crane Activity Monitoring and Alarming. Autom. Constr. 27: 111-119.

[49] J. Chen, Y. Fang, and Y. K. Cho. 2017. Real-time 3D Crane Workspace Update Using a Hybrid Visualization Approach. J. Comput. Civ. Eng. 31(5): 4017049.

[50] H. Li, G. Chan, and M. Skitmore. 2013. Integrating Real Time Positioning Systems to Improve Blind Lifting and Loading Crane Operations. Constr. Manag. Econ. 31 (6): 596-605.

[51] X. Luo, F. Leite, and W. J. O'Brien. 2015. Location-aware Sensor Data Error Impact on Autonomous Crane Safety Monitoring. J. Comput. Civ. Eng. 29(4): B4014010.

[52] H. Guo, Y. YU, T. Xiang, H. Li, and D. Zhang. 2017. The Availability of Wearable-device-based Physical Data for the Measurement of Construction Workers' Psychological Status on Site: From the Perspective of Safety Management. Autom. Constr. 82: 207-217.

[53] N. Soltanmohammadlou, S. Sadeghi, C. K. H. Hon, and F. Mokhtarpour-Khanghah. 2019. Real-time Locating Systems and Safety in Construction Sites: A Literature Review. Saf. Sci. 17: 229-242.

[54] R. Kanan, O. Elhassan, and R. Bensalem. 2018. An loT-based Autonomous System for Workers' Safety in Construction Sites with Real-time Alarming, Monitoring, and Positioning Strategies. Autom. Constr. 88: 73-86.

[55] J. Rekittke, P. Paar, E. Lin, and Y. Ninsalam. 2013. Digital Reconnaissance. J. Landsc. Archit. 8(1): 74-81.

[56] L. Klein, N. Li, and B. Becerik-Gerber. 2012. Imaged-based Verification of as-built Documentation of Operational Buildings. Autom. Constr. 21: 161-171.

[57] T. M. Ravich. 2013. Commercial Drones and the Phantom Menace. J. Int'l Media Ent. L. 5: 175

[58] W.-C. Chiang, Y. Li, J. Shang, and T. L. Urban. 2019. Impact of Drone Delivery on Sustainability and Cost: Realizing the UAV Potential through Vehicle Routing Optimization. Appl.
Energy. 242: 1164-1175.

[59] E. Natalizio, N. R. Zema, E. Yanmaz, L. D. P. Pugliese, and F. Guerriero. 2019. Take the Field from your Smartphone: Leveraging UAVs for Event Filming. IEEE Trans. Mob. Comput. 19(8): 1971-1983.

[60] P. M. Asaro. 2013. The Labor of Surveillance and Bureaucratized Killing: New Subjectivities of Military Drone Operators. Soc. Semiot. 23(2): 196-224.

[61] M. N. Boukoberine, Z. Zhou, and M. Benbouzid. 2019. A Critical Review on Unmanned Aerial Vehicles Power Supply and Energy Management: Solutions, Strategies, and Prospects. Appl. Energy. 255: 113823.

[62] R. Merkert and J. Bushell. 2020. Managing the Drone Revolution: A Systematic Literature Review into the Current Use of Airborne Drones and Future Strategic Directions for Their Effective Control. J. air Transp. Manag. 89: 101929.

[63] M. Tremayne and A. Clark. 2014. New Perspectives from the Sky: Unmanned Aerial Vehicles and Journalism. Digit. Journal. 2(2): 232-246.

[64] N. D. Opfer and D. R. Shields. 2014. Unmanned Aerial Vehicle Applications and Issues for Construction. 2014 ASEE Annual Conference \& Exposition. 24-1302.

[65] T. Rakha and A. Gorodetsky. 2018. Review of Unmanned Aerial System (UAS) Applications in the Built Environment: Towards Automated Building Inspection Procedures using Drones. Autom. Constr. 93: 252-264.

[66] M. M. Alsamarraie. 2021. The Application of the Seismic Method in Site Properties Assessment. Journal of Physics: Conference Series. 1892(1): 12025

[67] Z. M. Hatem. 2020. Management and Maintenance of the Welfare Facilities at Construction Sites in Iraq. Universiti Teknologi Malaysia.

[68] E. Ciampa, L. De Vito, and M. R. Pecce. 2019. Practical Issues on the Use of Drones for Construction Inspections. Journal of Physics: Conference Series. 1249(1): 12016. 